\title{
Nexo biopsíquico bumano no contexto dos catadores de lixo de uma associação do município de Arapiraca-AL
}

\section{| ${ }^{1}$ Diego de Oliveira Souza, ${ }^{2}$ Lucas Barros dos Santos |}

Resumo: O objetivo do estudo foi analisar o nexo biopsíquico humano dos catadores de material reciclável de uma associação. Trata-se de estudo de abordagem qualitativa, realizado em 2017, no município de Arapiraca-AL. A partir de um roteiro de entrevista semiestruturada, foram entrevistados sete catadores. O roteiro abordou quatro eixos: sociodemográfico, processo de trabalho, consequências da atividade de catação e condiçóes gerais de vida, possibilitando reunir elementos para analisar o "nexo biopsíquico humano" desse grupo, conforme a proposta de Laurell e Noriega. Foi possível identificar algumas das cargas de trabalho que os catadores estão expostos, como as mecânicas, psíquicas e fisiológicas relacionadas à organização do processo de trabalho. O fenômeno da "normalidade sofrente" se faz presente entre os catadores, consubstanciando uma espécie de mecanismo de pseudoproteção da atividade que, embora provoque adoecimento, oferece-lhes algum sustento. Também foram identificadas as cargas biológicas, pelo contato de material contaminado, perfurocortantes e insetos. As cargas de trabalho compóem um processo mais amplo no qual as condiçôes gerais de vida potencializam o processo de desgaste e adoecimento, porquanto esses catadores enfrentem problemas sociais como falta de saneamento, segurança, saúde e educação. Portanto, constitui-se um "nexo biopsíquico humano" no qual a doença se sobrepóe à saúde.

> Palavras-chave: catadores; condições sociais; saúde do trabalhador.
1 Universidade Federal de Alagoas. Arapiraca-AL, Brasil (diego. souza@arapiraca.ufal.br). ORCID: 0000-0002-1103-5474

${ }^{2}$ Universidade Federal de Alagoas Arapiraca-AL, Brasil (lucas barros55@hotmail.com). ORCID: 0000-0002-4719-598X

Recebido em: 16/12/2019 Aprovado em: 03/03/2020 Revisado em: 30/06/2020 


\section{Introdução}

O capitalismo, em especial nas economias periféricas, é repleto de desigualdades sociais, desde as de cunho econômico até as de caráter ideológico. A perspectiva marxiana tem se dedicado a analisar a estrutura e a dinâmica dessa sociedade, no intuito de desvelar suas determinaçôes mais essenciais, mas também suas expressóes fenomênicas. Essa perspectiva teórico-metodológica coloca o Modo de Produção Capitalista (MPC) no cerne da discussão, por ele se constituir a partir da forma de trabalho mais desigual já experimentada na história humana. Isto porque na mesma proporção que ela produz riqueza, em um patamar inédito, produz o pauperismo daqueles que a produziram (MARX,1988a; 1988b).

Em suma, Marx (1988b) explica como a separação entre meios de produção e produtores direto (implicando a formação de duas classes sociais fundamentais: burguesia ou proprietários dos meios de produção e proletariado, aqueles que só possuem sua força de trabalho) possibilita o processo de acumulaçáo de riqueza em função da pauperização de quem a produz.

Quando se trata das categorias profissionais que dependem do lixo para sobreviver, deve-se considerar que elas habitam a esfera do pauperismo absoluto. Grande parte dos indivíduos que constituem essas categorias profissionais são provenientes do lumpemploretariado - aquela camada do proletariado que fica à margem do mercado assalariado, perdendo a capacidade de valorizar sua força de trabalho (MARX, 1998b). Se no proletariado em geral temos um pauperismo, por vezes, relativo (uma vez que seu salário pode aumentar em termos absolutos, mas decresce em relação ao montante que a exploração do seu trabalho produz), o lumpemproletariado é lançado ao pauperismo absoluto, no qual não consegue sequer se inserir no jogo mercantil necessário ao atendimento de suas necessidades. A essa população excedente, restam alternativas como viver de empregos precários e subumanos, ou até mesmo em situação de mendicância, marginalidade etc. Nesse processo, situamos as origens do "trabalho" da catação de lixo enquanto alternativa de sobrevivência.

Sobre os catadores, em específico, é preciso dizer que no Brasil, segundo Dagnino e Johansen (2017), existem mais de 171.500 catadores informais atuando em ruas e lixóes, dos quais, de acordo com Pinhel (2013), cerca de 30.000 estáo organizados em cooperativas ou associaçôes. Para esse autor: 


\begin{abstract}
Constituem uma massa de desempregados que, por sua idade, condição social ou baixa escolaridade, não encontram mais lugar no mercado de trabalho formal. Existem, ainda, aqueles que, a despeito de serem um pouco mais escolarizados, também não conseguem uma posição profissional num mundo marcado pelo compasso tecnológico e digital. Por fim, há um grupo de homens e mulheres com histórias de vida muitas vezes assinaladas pela violência, pelo sofrimento e pelo preconceito (PINHEL, 2013, p. 18).
\end{abstract}

Têm-se constituído, enquanto tentativa de minimizar os fatores aviltantes do trabalho de coletar material reciclável, formas coletivas de organização econômica, a exemplo das cooperativas e associaçóes. Estas surgem com o objetivo de organizar o trabalho dos catadores, que desde já são muito fragilizados perante a sociedade, e isso notadamente se agrava quando atuam individualmente. Para Benvindo (2010), o trabalho conjunto realizado pelos catadores permite a materialização de uma identidade e compartilhamento de interesses, inclusive influindo financeiramente.

Pode-se dizer que os catadores de materiais recicláveis são subdivididos em três categorias: catadores de rua, catadores cooperados e catadores de lixão. Este estudo se debruçou sobre a situação de catadores cooperados/associados, residentes no município de Arapiraca, estado de Alagoas, com vistas a estabelecer correlaçôes entre o tipo de trabalho que desenvolvem, suas condiçõos de reprodução social e, consequentemente, de saúde. Para tanto, convém esclarecer que se trata de uma categoria profissional na qual se manifestam as determinaçóes mais severas do caráter destrutivo do capital sobre a saúde. Esse processo só pode, então, ser problematizado a partir de uma perspectiva que reconheça que a saúde possui uma dimensão social. Ou seja, o processo saúde-doença comparece enquanto expressão do caráter degradante do modo como se organiza a sociedade. Considerando essa perspectiva, o trabalho se coloca como categoria central, não só porque tem provocado adoecimento durante sua realização, mas porque está na base de todo processo de reprodução social, determinando formas de se viver que contribuem para a degradação da saúde (SOUZA, 2016).

Nesse quesito, Laurell e Noriega (1989) trazem os conceitos de cargas de trabalho e desgaste, destacando que "carga de trabalho" é uma categoria teórica utilizada para designar as condiçóes ambientais e os elementos que interagem entre si e o trabalhador, gerando processos de adaptação, que se traduzem em desgaste, não sendo possível apreendê-los através de um único artifício, por ser um fenômeno complexo. Dessa forma, as cargas de trabalho se dividem em físicas, químicas, 
biológicas e mecânicas de um lado e, por outro, fisiológicas e psíquicas. A partir disso, constitui-se o "desgaste", enquanto um processo de "[...] transformaçôes negativas, originadas pela interação dinâmica de cargas, nos processos biopsíquicos humanos. O desgaste pode ser definido então, como a perda da capacidade efetiva e/ou potencial, biológica e psíquica." (LAURELL; NORIEGA, 1989, p. 109-115).

Para além dos elementos degradantes existentes no interior do processo de trabalho, há de se considerar os elementos degradantes na vida em geral, que se interseccionam na determinação social da saúde. Essa articulação entre condiçôes de trabalho e os elementos da reprodução social dos trabalhadores (o que inclui condiçôes de moradia, alimentação, vestuário etc.) consiste no que Laurell e Noriega (1989) chamaram de "nexo biopsíquico humano". É este último, no contexto dos catadores de materiais recicláveis da Associação de Resíduos Sólidos de Arapiraca (ASCARA), que define o nosso problema de pesquisa.

Considerando esse referencial teórico, o objetivo do artigo é analisar o nexo biopsíquico humano dos catadores de materiais recicláveis de uma associação de catadores de material reciclável.

\section{Procedimentos metodológicos}

Este trabalho é de abordagem qualitativa, uma vez que estuda o fenômeno em questão a partir da subjetividade dos sujeitos envolvidos, embora não deixe de considerar as determinaçôes objetivas que estão imbricadas na subjetividade estudada. Salienta-se que aqui tomamos a categoria "subjetividade" no sentido marxiano, enquanto esfera da realidade genuinamente expressa nos sujeitos históricos, mas que se constitui, dialeticamente, por meio do confronto, individual e coletivamente, ante a realidade objetiva, na sua materialidade exterior aos sujeitos. Na perspectiva de práxis, subjetividade e objetividade (sujeitos e realidade objetiva) estão em mútua determinação, mas com prioridade ontológica para a objetividade (LUKÁCS, 2012).

A pesquisa foi realizada na sede da Associação de Resíduos Sólidos de Arapiraca (ASCARA), que fica situada no sítio Mocó, distrito de Arapiraca, com um grupo de sete catadores entre os 11 associados ativos, à época. Foi escolhido um dia em que todos estivessem na associação para uma conversa inicial de apresentação da pesquisa e aproximação do pesquisador com os trabalhadores. Nesse processo de aproximação, explicamos como seria realizada a coleta de dados, qual o objetivo pretendido e os 
desdobramentos possíveis. Em outro dia, previamente agendado, realizamos a entrevista individual com os catadores. Os sujeitos que se negaram a participar foram respeitados (os motivos alegados estiveram atrelados à necessidade de realizar outras atividades no mesmo horário), sendo excluídos da pesquisa (quatro indivíduos).

Foi utilizado um questionário sociodemográfico para levantar dados sobre a população em estudo (de caráter assessório) e, junto ao mesmo, o roteiro semiestruturado abordando questôes sobre o ambiente e processo de trabalho, bem como as condiçóes gerais de vida. A entrevista foi gravada em áudio para posterior análise. Esta, por sua vez, se deu conforme proposta de Laurell e Noriega (1989), ancorada na perspectiva materialista histórica.

Identificaram-se os núcleos temáticos que se apresentam nas falas dos sujeitos de pesquisa, agrupando-as segundo suas similitudes. Trechos das falas dos participantes são citados na discussão deste artigo, mas conservando sua identidade, para o que se utilizaram os códigos $\mathrm{C} 1$ a C7 para indicá-los, e $\mathrm{P}$ para indicar as falas do pesquisador. Mantiveram-se, literalmente, as palavras utilizadas pelos entrevistados, destacando entre aspas palavras que não seguem as regras ortográficas da língua portuguesa.

Depois disso, buscou-se fazer inferências sobre seus significados, tendo por base o contexto social particular que se inserem, mas também a dinâmica social em geral do MPC. Para tanto, nossa plataforma analítica e interpretativa foi a teoria social de Marx. Trata-se do movimento de "ida-e-volta” debatido por Lukács (2012), quando o pesquisador se debruça sobre o objeto de estudo em particular, decompondo-o, para, posteriormente, fazer sua recomposição, estabelecendo analogias tendo como parâmetro a esfera da universalidade. Nesse movimento, cabe destacar, a categoria trabalho comparece com prioridade ontológica, tendo em vista seu caráter fundante ante a sociedade, mas sempre em interaçáo dialética com os outros complexos sociais.

Por fim, destacamos que o projeto de pesquisa foi aprovado pelo Comitê de Ética e Pesquisa - CEP da UFAL, parecer n. 62266016.1.0000.5013.

\section{O processo de trabalho dos catadores de materiais recicláveis da ASCARA: cargas e desgaste}

Inicialmente, cabe mencionar o perfil dos sujeitos da pesquisa, quando foi possível observar que seis dos entrevistados são do sexo feminino (sendo quatro catadoras casadas e duas solteiras) e apenas um é do sexo masculino (solteiro), com faixa etária de 25 e 59 anos (média de 40,5 anos). 
Em relação ao sexo, convém destacar que embora a natureza qualitativa do estudo inviabilize comparaçóes genéricas do perfil traçado, a presença maior de mulheres na ASCARA é fator suscitador de reflexão, inclusive a ser recuperada em investigaçôes futuras. Por ora, vale destacar que, segundo Silva, Goes e Alvarez (2013), no Nordeste, a maioria dos catadores é de homens, mas apesar disso, fatores ligados à realidade particular do grupo estudado podem se apresentar como indícios explicativos para a maior adesão feminina. Por exemplo, a presença de uma creche na comunidade Mangabeira (na qual residem todos os entrevistados) onde as mulheres (no caso aqui em questão, uma delas com filho em idade pré-escolar) podem deixar os seus filhos e, assim, trabalharem. Da mesma forma, as crianças em idade escolar (nesta pesquisa, três mulheres possuíam filhos em idade escolar) frequentam a escola de ensino fundamental existente na comunidade, viabilizando a inserção de suas mães em alguma atividade laboral.

Já em relação à renda individual dos entrevistados, esta variou entre $\mathrm{R} \$ 150,00$ e 250,00. Convém salientar que, em geral, esses trabalhadores possuem baixos rendimentos, a exemplo da média constatada na Região Nordeste, onde possuem renda inferior a R\$ 476,00 (SILVA; GOES; ALVAREZ, 2013).

Sobre a questão étnico-racial dos entrevistados, quatro se autodeclararam pardos, dois negros e um branco. Silva, Goes e Alvarez (2013) destacam que os catadores, em geral, apresentam uma proporção maior de negros do que a população em geral, fator proveniente do histórico de exclusão social que permeia a história dessa etnia, em determinação recíproca com o desenvolvimento da atividade de catação e a desvalorização social que lhe é adjacente (aspectos que certamente influenciam os baixos rendimentos que possuem).

No Brasil, o negro sofre com a questão racial, que não se restringe apenas à época da escravidão, mas toda a violência sofrida por esta população até os dias atuais. Tal violência não se materializa apenas nas agressôes físicas e verbais, mas de várias formas de exclusão e inferiorização cultural. Após o fim da escravidão, os negros não tinham posses, terras, dinheiro ou sequer algum lugar para ir, aglomerando-se, assim, nas grandes cidades em morros e áreas mais afastadas, vivendo de forma miserável, o que consubstancia determinaçóes que os impelem a viver, por exemplo, da cataçáo do lixo, sobrevivendo do que a sociedade descarta (SILVA; NOBRE, 2017).

Além disso, observamos que a cidade de Arapiraca teve uma ascensão da cultura fumageira entre 1940 e 1970, empregando muitas pessoas na agricultura. 
A partir da década de 1980, essa cultura começou a enfraquecer economicamente, forçando os trabalhadores do ramo a migrarem para a cidade em busca de novas atividades laborais (a maioria sem qualificação profissional para o trabalho urbano) (CARVALHO; FERREIRA; GONÇALVES, 2016). Sem opção, muitos se inseriram no âmbito da catação no lixão da cidade e foram se alocando nos arredores, surgindo a comunidade Mangabeiras, sem nenhum planejamento e que hoje conta com cerca de 240 domicílios e 960 habitantes. Diante das dificuldades vivenciadas pelos catadores de lixo dessa comunidade, através de parceria entre a Universidade Federal de Alagoas (UFAL) e a prefeitura da cidade de Arapiraca, foi criada a ASCARA no ano de 2010 (CARVALHO; FERREIRA; GONÇALVES, 2016).

Nesse contexto, há um entrelaçamento de diversos fatores que constituem cargas de trabalho, desencadeando processos de desgaste dos catadores da ASCARA. Para identificar tais cargas, faz-se necessário entender os elementos básicos do processo de trabalho particular dos catadores. Um desses elementos diz respeito à jornada de trabalho, uma vez que seu prolongamento vem provocando desgaste do trabalhador desde a origem do capitalismo (MARX, 1988a). No que concerne aos catadores da ASCARA, constatou-se que não há uma duração de jornada de trabalho definida, uma vez que, enquanto existir demanda de materiais na associação, estes poderão ser processados pelos catadores. Mas, como podemos ver nas falas dos catadores, a jornada não costuma ultrapassar seis ou sete horas.

$$
\begin{aligned}
& \text { P - Qual sua carga horaria diária? } \\
& \text { C1 - Olha, a gente trabalha no máximo seis, sete "hora" por dia. } \\
& \text { C3 - Trabalho seis horas num dia, as vezes mais. }
\end{aligned}
$$

Aqui, destaca-se que o desgaste pelo trabalho pode estar ligado à jornada de trabalho extensa, mas também pode ser proveniente de sua instabilidade e precariedade (em termo quantitativo e/ou qualitativo). Como desdobramento, constatou-se que eles desempenham atividades independentes da associação, nos horários alternativos, a exemplo da noite. Vejamos:

P: Quais os seus turnos de trabalho?

C1: A gente trabalha de manhã e a tarde. No dia que a gente vai trabalhar a noite, a gente não vem "pá” associação. A gente só trabalha só a noite, só.

Com isso, há uma variação dos turnos de trabalho, pois a demanda é flexível e os trabalhadores têm que se adaptar a essa rotina. Outro ponto que vale ser ressaltado é 
que o fato de estar associado não elimina atividades extras (por fora do trabalho na ASCARA), nem o prolongamento da jornada (como o trabalho noturno).

Esse tipo instável de organização do trabalho, por si só, implica cargas fisiológicas e psíquicas, pois se caracteriza pela alternância de turnos (ou a intensidade dos turnos, que não tem uma materialidade visível) e se manifesta de forma negativa no corpo e mente do trabalhador, com ansiedade, crises de adaptabilidade, insônia, tensão muscular, fadiga, dores articulares e/ou em outras regióes do corpo (SELIGMANN-SILVA 2011).

Além da questão da jornada, constatamos que o processo de trabalho dos catadores se dá mediante variação de ambiente e etapas. Há pelo menos dois ambientes nos quais as açôes se dão predominantemente: 1) quando estão nas ruas, dedicam-se, sobremodo, à coleta de materiais, geralmente carregando-os em carroças; 2) o processo segue com a seleção daquilo que poderá ou não ser processado, para posterior preparo (em geral, compactação) e venda. Estas últimas etapas ocorrem na sede da ASCARA, associadas às atividades complementares de limpeza, manutenção e organização da própria associação. Os relatos a seguir resumem bem essa variação de ambientes e etapas:

$\mathrm{P}-\mathrm{O}$ que a faz aqui na associação?

C2 - Aqui eu faço tudo, eu "recicro", eu vou "pá” “vassora”, eu vou "pá” faxina. De cada coisa tem um pouquinho. Imprenso e cada coisa tem um pedacinho.

C5 - Vou pra rua catar, vou pra rua carregar carroça, de tudo eu tem um "poquinho".

Nesse caso, podemos observar a presença de cargas mecânicas no processo de trabalho dos catadores, predispondo-os aos acidentes de trabalho. $\mathrm{O}$ mesmo trabalhador possui muitas atribuiçôes, seja na sede da associação ou fora dela, da catação ao processamento, passando pela organização do ambiente de trabalho. Isso potencializa as cargas mecânicas, pois um único catador exerce diversas funçôes e que não são preestabelecidas ou sistematizadas no processo organizacional do trabalho, gerando inclusive excesso de responsabilidades ou tendência ao improviso.

Assim, há diversas possibilidades de acidentes, como no uso da prensa, da carroça, no ato de transitar na rua (muitas vezes, entre os carros) etc., o que se mostra ainda mais grave por conta do não uso de EPI:

P - Faz uso de EPI - Equipamento de Proteção Individual?

C1 - Não. Única coisa que só tem, só a farda, "pá” identificar e assim, essa farda já foi que a gente ganhou. 
C2 - Porque você sabe que pra nós tudo é um risco quando você trabalha "disequipado" ali. Você sabe? "Cê" "tá" esperando tudo, porque ali, quando eu boto a bolsa, quando eu abro aqui uma bolsa, eu já vou com cuidado num vidro, num pedaço de ferro na mão, aí eu já tenho que ir com aquele cuidado, num é? Eu já tenho que ir com aquele cuidado num é? Você, quando "tá" equipado, que você "tá" com uma luva, com uma bota, "né"? Tem muita diferença.

Diante dos relatos, percebe-se que os catadores apenas têm para sua proteção uma farda para identificação. A desproteção ao corpo do trabalhador abre a possibilidade de acidentes com consequências mais graves, o que foi reconhecido por eles mesmos. A desassistência e desproteção está diretamente ligada ao caráter informal no qual esse trabalho se dá, refletindo típica e acentuadamente a precarização enquanto elemento substancial da reestruturação produtiva ocorrida, mundialmente, da década de 1970 para cá.

A forma de organização do trabalho vem se modificando, afastando-se do (mas não eliminando o) binômio taylorista/fordista, no sentido de um modelo flexível de acumulação. No Brasil, isso se apresenta a partir da década de 1990, flexibilizando as relaçóes de trabalho, retirando direitos e aumentando a informalidade. Notase que essa flexibilização precariza ainda mais o processo de trabalho, amplia a competitividade, levando ao desgaste emocional de quem está nela inserido. Soma-se a isso as diversas crises de adaptação corolárias à instabilidade, abrindo diversas vias de exposição às cargas psíquicas, com o consequente desgaste mental que provocam (ALVES, 2005; SELIGMANN-SILVA, 2011).

É preciso, ainda, observar a questão da coleta dos materiais não recicláveis, mas que muitas vezes são coletados para consumo próprio do catador, a exemplo de alimentos e bebidas - fato comprovado entre nossos entrevistados:

$\mathrm{P}$ - Você Recolhe alimento do lixo e faz uso do mesmo?

C1 - Sim, a gente faz.

O alimento, quando descartado no lixo, não está apropriado para o consumo humano, podendo estar fora da validade, contaminado ou estragado, e gerar, com isso, doenças como intoxicaçóes, parasitoses e infecçóes gastrointestinais. Portando, o consumo ou, por vezes, o simples contato com matéria orgânica estragada ou contaminada determina a exposição do catador às cargas biológicas, sob a forma dos diversos agentes etiológicos responsáveis por doenças infecto-parasitárias (BRASIL, 2005; COELHO et al., 2018; MOREIRA; GÜNTER; SIQUEIRA, 2019). 
Acrescente-se a isso o potencial contato com substâncias tóxicas, como solventes e metais pesados (GOUVEIA et al., 2019).

Constata-se que os catadores, como no caso dos que participaram desta pesquisa, estão imersos em condiçôes nas quais suas necessidades nem sempre são atendidas, a exemplo da alimentação. Nesse sentido, o fato de buscarem a satisfação dessa necessidade naquilo que as outras pessoas descartam é emblemático dessa condição, revelando que esse grupo social se situa nas camadas mais pauperizadas da classe trabalhadora. No caso de catadores associados, tem-se uma situação menos deplorável, o que dá a medida de certa importância desse tipo de organização coletiva. Trabalhando de forma organizada e apenas com materiais recicláveis, estabelece-se outra relação com o lixo, ainda que com problemas estruturais.

Ainda sobre a alimentação, destaca-se como ela é realizada ao longo da jornada de trabalho que, como já apontado, é instável e indefinida. Porém, mesmo indefinidas, existem pausas para refeiçóes que são feitas no local de trabalho mesmo - refeição que eles trazem de suas residências para consumirem na sede da associação.

$\mathrm{P}-\mathrm{E}$ tem pausas durante o trabalho?

C1 - Tem. A gente larga "pá” almoçar e com uma hora de relógio a gente retorna ao trabalho.

$\mathrm{P}$ - Quais as fases do seu trabalho (se existem pausas, refeições e onde são feitas e se é no local de trabalho)?

C1 - Quando a gente vem pra "qui" "pa” associação a refeição são feitas no trabalho, era feita né? 'Mai" depois que "carregaro" o "fugáo" daqui, "carregaro" bujão a gente tamo trazendo a comida já pronta de casa já.

C6 - Era, hoje num é não, hoje é boia-fria "mermo"; hoje é boia-fria, que a gente "tamo" "ficamo" sem nada, "carregaro" tudo que "nóis" tinha: prato, "culé", tudo, tudo, dois bujão, dois fugão.

Ainda com a mesma pergunta, foi possível identificar outros tipos de pausas durante o processo de trabalho:

$\mathrm{P}-\mathrm{E}$ tem pausas durante o trabalho?

C4 - Tem, a gente para de onze e meia e a gente, quando a gente para a gente almoça, toma uma "fuguinha" "pa" poder voltar de novo a atividade.

A questão organizacional do trabalho comparece novamente na situação relatada, nesse caso com o uso das pausas para reestabelecer a força de trabalho. Quando o entrevistado relata uma "fuguinha" durante o trabalho (do verbo fugir), denota-se 
o sentido de aprisionamento que o trabalho assume na sua vida, inclusive revelando seu caráter de brevidade, expresso pelo termo no diminutivo "fuguinha". Ou seja, trata-se de uma "fuga” temporária que serve para reposição e regeneração da força de trabalho, para que o trabalhador retorne à sua atividade o mais rápido possível.

Como relata Alves (2005), o "não perder tempo" é introjetado pela subjetividade do trabalhador, obrigando a acelerar a produção e evitar pausas longas, configurando cargas de cunho psíquico. Para o autor, isso desemboca em uma série de problemas psicoemocionais, como estresse, irritabilidade, cansaço mental, transtornos do sono e ansiedade.

Ainda na questão das cargas psíquicas, fica explicitado que os catadores têm ciência das cargas de trabalho que estão expostos diariamente, mas se contradizem quando questionados se já adoeceram por conta do trabalho, o que pode ter influência de fatores subjetivos, pelos quais o processo de adoecimento é considerado um fato normal pelos catadores. Essa condição pode ser um mecanismo de normalizar ou amenizar a condição de sofrimento para a qual eles são impelidos (DEJOURS, 2006). Um primeiro passo para identificar tal processo é entender, na perspectiva deles mesmos, o porquê de entrarem no universo da catação:

$\mathrm{P}$ - Por você que faz da catação uma atividade de trabalho?

C1 - Porque é a única, é a única, é a única fonte de renda que eu tenho pra, pra trabalhar é essa.

C2 - Ah! Deixa eu te dizer, 'ói”! Assim, antes eu era uma pessoa que eu "trabaiava” em firma de fumo, aí hoje eu, assim, já trabalhei na creche, passei sete ano trabalhando numa creche. Mas o importante é pra mim, eu acho assim, é eu, é eu ser uma pessoa individual, num "pidir" nada, tá esperando que ninguém me mande tá fazendo isso. Eu acho até que num dá certo. "Num" pode, como é? Assim, eu trabalho do jeito que eu quero, do jeito que eu posso, faço o que eu quero, faço o que eu gosto, faço a limpeza, faço tudo, então por isso que eu acho melhor trabalhar assim.

Nos trechos citados há indícios importantes sobre o processo de determinação da "normalidade sofrente" desses catadores, impelidos a uma atividade insalubre por não terem opçóes na dinâmica de acumulação capitalista. Formam-se nexos causais entre (cargas do) processo de trabalho e saúde que se agravam devido à normalização do processo, incorporada subjetivamente pelo catador; marcada pela dominação social típica do capitalismo (DEJOURS, 2006).

O sofrimento chega a um patamar tão elevado que gera mecanismos de uma pseudoproteção psíquica, a partir dos quais o indivíduo aceita seu sofrimento como 
normal para não ameaçar a continuidade da atividade que permite sua sobrevivência. Destaca-se que a "normalidade sofrente" não quer dizer, simplesmente, que o indivíduo não reconheça que adoece ou sofre, mas que essa condição se tornou normal. Como pode ser visto a seguir, alguns catadores identificam a relação entre o seu adoecimento e o trabalho, apesar da normalização.

$\mathrm{P}-\mathrm{Quais}$ as outras situaçôes do seu dia a dia do trabalho que podem levar ao adoecimento? C1 - Eu acho que o trabalho que a gente faz é um trabalho, é de risco, tá entendendo? Porque a gente pega em diversas coisas quando a gente vai catar o material.

C6 - Rapaz, eu acho que a gente pode "aduecer", mas assim acho que "divido" a gente num trabalhar com luva, a gente num trabalha com bota, a gente trabalha normalmente, aí muitas vezes aparece escorpião, aí é essas parte aí que a gente acha que pode "acontece" por conta disso.

Constata-se que os catadores estão cientes de algumas cargas a que estão expostos diariamente e possíveis consequências. Eles mostram clareza no entendimento de que podem adoecer e se acidentar, mas a "normalidade sofrente" pode avançar a níveis nos quais tudo isso é tão normal que não precisa ser destacado:

$$
\begin{aligned}
& \text { P - Já adoeceu por causa do trabalho? Se sim, de que você adoeceu? } \\
& \text { C1 - Assim, catando material? Não. } \\
& \text { C2 - Não, não, não adoeci não. } \\
& \text { C3 - Não. } \\
& \text { C4 - Acho que não. } \\
& \text { C7 - Adoeço "mai" "pôque" falta o básico "dentru" de casa. }
\end{aligned}
$$

Nota-se que, embora admitam que existem cargas de trabalho e que estas podem levar ao adoecimento, os catadores não reconhecem já terem adoecido por conta delas. Essa condição está associada à defesa da atividade que garante (ainda que precariamente) a sobrevivência, mas revela a necessidade urgente de se discutir e criar intervençôes que equalizem essa questáo entre os catadores. É preciso que os serviços de saúde, em especial aqueles que são nucleares na Rede de Atenção Integral à Saúde do Trabalhador (RENAST), articulem-se com as associaçôes de catadores, a fim de desenvolver trabalhos educativos, fornecer EPI e medidas de prevenção em geral, além de encaminhá-los para os tratamentos de saúde cabíveis. Ademais, é preciso fortalecer toda uma rede de serviços para além do setor saúde, pois as condiçôes de vida em geral estáo associadas ao processo saúde-doença, como abordado a seguir. 


\section{Das condiçôes gerais de vida dos catadores de materiais da ASCARA: desvelando o nexobiopsíquico humano}

Os trabalhadores da ASCARA moram vizinhos ao antigo lixão de Arapiraca, o que poderia gerar desconforto pelo contato permanente com o lixo ou, em especial, devido à falta de condiçôes básicas de moradia e saneamento básico - mesmo assim, os catadores indicam uma suposta habituação ao ambiente:

$\mathrm{P}$ - Como é o local que você mora?

C2 - É, deixa eu te dizer, o local que eu moro, que eu moro num tem aquele, tomara que num chova num é? "Cê” pede a deus que num chova, entâo é a minha situação e agradeço tudo a deus, peço a ele todo dia.

C4 - A mangabeira? É um bom lugar, eu gosto de morar lá, a verdade é essa e depois que fechou o lixão aí ficou ruim, né? "Puquê" a gente, "condo" "nóis" num tava aqui na associação, a gente tava lá no lixão, "catano” lá no lixo.

Antes de iniciar a pesquisa com os trabalhadores da ASCARA, foram realizadas algumas visitas na comunidade Mangabeiras, para aproximação ao contexto em que os catadores vivem; nessas visitas foi possível constatar a existência de condiçôes precárias, como casas feitas de materiais encontrados no lixo, saneamento básico e água potável ausentes, dentre outras inúmeras complicaçóes. A entrevista realizada com os trabalhadores ratifica tal condição, como por exemplo, quando destacam que a falta de saneamento é um dos principais problemas:

$\mathrm{P}$ - Como é o local que você mora?

C1 - O local que a gente mora é, é um local que fica perto do lixão e hoje melhorou um pouco, né? E a única coisa que tá faltando pra nossa comunidade melhorar mais é fazer o saneamento básico, é o que todos os moradores quer da comunidade é o saneamento básico, porque dá mais melhoria de vida ao morador, principalmente pras criança, né?

$\mathrm{C} 7$ - O difícil é que não tem saneamento.

De acordo com um estudo feito em um município da Bahia, a maioria dos catadores residem em locais que não possuem água encanada e saneamento básico (DOBRACHINSKI; DOBRACHINSKI, 2013). A falta de saneamento básico e água potável para consumo humano pode gerar diversas doenças, seja de caráter infeccioso e/ou parasitárias, pois o meio favorece e contribui com o ciclo de determinadas doenças como: diarreia, verminoses, dengue, zika, chicungunya, hepatites infecciosas, cólera dentre outras. 
Diante desse contexto, no qual as necessidades básicas são negadas, a existência de serviços públicos (como os de educação, saúde e segurança) se faz um elemento importante para o enfrentamento das dificuldades sociais. Nesse bojo, destaca-se que a comunidade Mangabeira possui creche e escola de ensino básico, consoante os relatos dos próprios catadores:

$$
\begin{aligned}
& \text { P - Você tem acesso ao serviço de educação? } \\
& \text { C1 - Tem escola e tem creche. } \\
& \text { C4 - Sim, tem escola e creche "pras" crianças, aí é mais fácil pra gente trabalhar. }
\end{aligned}
$$

Sabe-se que a educação tem o potencial de contribuir para a transformação social, abrangente e emancipadora. Essa transformação é inconcebível sem uma ativa contribuição da educaçáo no seu amplo sentido (MÉSZÁROS, 2005). No caso dos catadores que compóem o lumpemproletariado, empoderar e se fortalecer enquanto cooperados se faz importante, sendo a educação um dos complexos decisivos para entenderem sua própria condição.

Em relação ao serviço de saúde, os catadores afirmam ter acesso à Unidade de Atenção Básica:

$$
\begin{aligned}
& \text { P - Você possui acesso ao serviço de saúde? } \\
& \text { C2 - Sim. } \\
& \text { C3 - Tem o posto. } \\
& \text { C7 - Tem, "nóis" tem posto de saúde. }
\end{aligned}
$$

É importante que a comunidade de Mangabeira tenha acesso ao serviço de atenção básica à saúde, onde se desenvolvem ações de promoção e proteção da saúde, prevenção de agravos, diagnóstico, tratamento, reabilitação e manutenção da saúde, com potencial de resolver cerca de $80 \%$ dos problemas de saúde pública (BRASIL, 2012).

Já em relação à segurança, os moradores da comunidade referiram que não têm acesso à segurança pública. Há poucos estudos no que se refere à questão da segurança de comunidades em torno de lixões, como é o caso da Mangabeira. Todavia, um estudo realizado em Itacaré, na Bahia, mostra que 80\% dos moradores relataram não existir presença da segurança pública onde residem (BARROS, 2015). No caso da Mangabeira, a situação se confirma:

$$
\mathrm{P} \text { - Você tem acesso ao serviço de segurança? }
$$




$$
\begin{aligned}
& \text { C2 - Não, tem não. } \\
& \text { C4 - Não. E aqui já teve morte. }
\end{aligned}
$$

A violência incide diretamente sobre populações que vivem em regiôes à margem das cidades, como os catadores (PINHEL, 2013), o que está diretamente ligado à saúde, seja pelos danos diretamente provocados ao corpo, quando se é vítima da violência, seja pela sensação de insegurança no cotidiano e as consequências psicoemocionais que pode gerar.

Em relação à alimentação dos catadores, de um modo geral, ou seja, aquela que ocorre quando não estão especificamente no trabalho, foi possível fazer algumas constataçóes.

$\mathrm{P}$ - Como é a sua alimentação? Tem as três refeiçôes do dia?

C2 - "Ói", quando tem, faço, quando num tem, num faço. "Cê sabe", a pobreza hoje, ela é, né? E quando você num tem salário, pior, né?

Alguns dos entrevistados não fazem nem as três refeiçôes principais do dia, muito provavelmente pelo fato de não terem condiçôes financeiras para tal. Essa condição é um fator agravante do desgaste do trabalhador, colocando-os suscetíveis à condição de continuar ou retornar a busca de alimentos no lixo, mesmo estando associados e trabalhando com foco nos materiais recicláveis.

Já foi constatado que a maioria dos catadores faz uso de alimento coletado no lixo (HOEFEL et al., 2013). No nosso estudo, um catador referiu fazer coleta de alimento do lixo para consumo. Sabendo que os demais nem sempre possuem as três refeições diárias, esse número pode ser maior, situação comum no contexto de pobreza, consoante autorrelatado por $\mathrm{C} 2$.

Quando se trata do lazer dos trabalhadores da ASCARA e moradores da comunidade Mangabeira, todos referiram não ter atividades de lazer aos finais de semana ou quando não estão trabalhando:

$\mathrm{P}$ - Você tem atividades de lazer?

C1 - Fico em casa, é o que tá faltando também dentro da nossa comunidade, também é uma, é uma área de lazer pras criança e "pa" os pais também, né? Levar as criança pra se divertir, né?.

C2 - Também não, não conheço essa parte, o lazer meu é o dia a dia.

C7 - Não. 
É importante destacar que todo lazer é prática cultural, assistida ou conhecida em tempo e espaços livres, que oferece possibilidades de descanso, divertimento e desenvolvimento individual e coletivo, o que pressupóe organização social (com intervenção estatal) para tal, mas que esbarra na lógica de reprodução social do capital, direcionada à acumulação de riqueza. Inclusive, essa condição resulta em acesso ou não as melhores formas de lazer disponíveis no ideário social, numa fase histórica. Portanto, tal condição atravessa e compromete diretamente o acesso ao lazer por parte dos catadores, com implicaçôes, por exemplo, para sua saúde mental e recuperação física.

Não possuir acesso a esses serviços públicos potencializa o desgaste que o trabalhador sofre no seu trabalho, criando nexos biopisíquicos aviltantes. Assim, perde-se a saúde, seja diretamente no processo de trabalho, seja pelas condiçóes gerais de vida, agravadas pela desassistência do Estado.

\section{Considerações finais}

Constatou-se que a ASCARA é constituída, em sua maioria, por mulheres, negras ou pardas, com baixo grau de escolaridade, idades que variam de 25 a 59 anos. Hoje são trabalhadores cooperados e possuem uma renda mensal individual que vai de $\mathrm{R} \$ 150,00$ a $\mathrm{R} \$ 250,00$. Todos os catadores que participaram da pesquisa moram na comunidade Mangabeira.

O nexo biopsíquico humano dos catadores é determinado pelas cargas de trabalho típicas da atividade da catação, quando se destacam aquelas ligadas à questão organizacional e que se desdobram, sobretudo, em cargas fisiológicas e cargas mecânicas. Os catadores estão submetidos, também, às cargas biológicas, com insetos e perfurocortantes presente no lixo ou pelo processo de putrefação de matéria orgânica, predispondo-os a doenças parasitárias e gastrointestinais.

Quando se trata das cargas psíquicas, constataram-se indícios significativos de um processo de "normalidade sofrente", fazendo-se uso de mecanismos de pseudoproteçấo psíquica no sentido de não assumir o caráter adoecedor da atividade que desempenham. E sobre as condiçôes gerais de vida dos catadores, destacam-se questôes ligadas à falta de planejamento urbano, em especial o saneamento básico. Apesar de condiçốes de vida tão precárias, os catadores têm acesso a alguns serviços públicos básicos, pois na comunidade há uma escola e uma creche, assim como uma 
unidade de saúde que faz atendimento básico naquela região. Todavia, afirmam não existir acesso à segurança pública e opçôes de lazer.

Destaca-se que o estudo enfrentou dificuldades com a quantidade de sujeitos participantes na pesquisa, considerando a volatilidade no número de membros ativos na associação, o que implica a necessidade de um acompanhamento mais duradouro. Apesar disso, contribuiu-se para demonstrar que o nexo biopsíquico dos catadores se constitui a partir de relevantes cargas de trabalho em sinergia com graves problemas sociais, compondo um processo peculiar às camadas mais afetadas pela desigualdade social que é estrutural do MPC.

Faz-se necessário realizar pesquisas que promovam a investigação in loco mais prolongada do processo de trabalho, das atividades que os catadores desempenham, apreendendo outras cargas de trabalho que não comparecem nas narrativas dos próprios catadores. Da mesma forma, é preciso investigar as condições gerais de vida, particularizando o acesso (ou a falta dele) aos vários serviços públicos. Com base no aprofundamento dessas mediaçóes, poder-se-á prosseguir com as possíveis macrocorrelaçôes estabelecidas com o MPC, contribuindo para entendê-lo e transformá-lo. ${ }^{1}$

\section{Referências}

ALVES, G. Trabalho, corpo e subjetividade: toyotismo e formas de precariedade no capitalismo global. Trabalho, Educação e Saúde, v. 3, n. 2, 2005.

BARROS, I. C. Riscos socioambientais e de saúde: representaçóes sociais dos moradores do entorno do lixão em um município sul baiano. Dissertação (Mestrado) - Universidade Estadual de Santa Cruz. Ilhéus-BA, 2015.

BENVINDO, A. Z. A nomeação no processo de construção do catador como ator econômico e social. 2010. Dissertação (Mestrado) - Universidade de Brasília. Brasília, 2010.

BRASIL. Ministério da Saúde. Cuidado com os alimentos. Brasília: NUT/FS/UnB, 2005.

. Ministério da Saúde. Política Nacional de Atenção Básica. Brasília: Secretaria de Atenção à Saúde, Departamento de Atenção Básica, 2012.

CARVALHO, A.; FERREIRA, D.; GONÇALVES, T. Às margens do lixão, a comunidade Mangabeira em Arapiraca-AL soba ótica e suas precariedades. In: Congresso Luso Brasileiro para o Planejamento Urbano, Regional, Integrado e Sustentável - contrastes, condiçóes e complexidades. Anais... Maceió-AL, 2016. 
COELHO, A. P. F. et al. Cargas de trabalho de catadoras de materiais recicláveis: propostas para o cuidado de enfermagem. Revista Gaúcha de Enfermagem, v. 30: e2018-0006, 2018.

DAGNINO, R. de S.; JOHANSEN, I. C. Os catadores no Brasil: características sociodemográficas e econômicas dos coletores de material reciclável, classificadores de resíduos e varredores a partir do Censo Demográfico de 2010. In: MINISTÉRIO DO TRABALHO. Instituto de Pesquisas Econômicas Aplicadas. Mercado de trabalho: Conjuntura e Análise. Brasília: IPEA, 2017. p. 115-125.

DEJOURS, C. A banalização da injustiça social. Rio de Janeiro: FGV, 2006.

DOBRACHINSKI, L.; DOBRACHINSKI, M. M. Condiçóes de vida, trabalho e saúde dos catadores de materiais recicláveis do lixão de um município do oeste da Bahia. Rev. das Ciências da Saúde do Oeste Baiano - Higia, v. 1 n. 1, p. 18-45, 2016.

GOUVEIA, N. et al. Exposição ocupacional ao mercúrio em cooperativas de triagem de materiais recicláveis da regiâo metropolitana de São Paulo, SP, Brasil. Ciência de Saúde Coletiva, v. 24, n. 4, p 1517-1526, 2019.

HOEFEL, M. da G. et al. Acidentes de trabalho e condiçóes de vida de catadores de resíduos sólidos recicláveis no lixão do Distrito Federal. Rev. Brasileira de Epidemiologia, v. 16, n.3, p 764-785, 2013.

LAURELL, A. C.; NORIEGA, M. Processo de produção e saúde: trabalho e desgaste operário. São Paulo: Hucitec, 1989.

LUKÁCS, G. Para uma ontologia do ser social I. São Paulo: Boitempo, 2012.

MARX, K. O Capital: crítica da economia política. Livro Primeiro. Tomo 1. São Paulo: Abril Cultural, 1988a.

MARX, K. O Capital: crítica da economia política. Livro Primeiro. Tomo 2. São Paulo: Abril Cultural, 1988b.

MÉSZÁROS, I. A educação para além do capital. São Paulo: Boitempo, 2005.

MOREIRA, A. M. M.; GÜNTHER, W. M.; SIQUEIRA, C. E. Workers' perception of hazards on recycling sorting facilities in São Paulo, Brazil. Ciência e Saúde Coletiva, v. 24, n. 3, p. 771-780, 2019.

PINHEL, J. R. (Org.). Do lixo à cidadania: guia para formação de cooperativas de catadores de materiais recicláveis. São Paulo: Editora Peirópolis, 2013.

SELIGMANN-SILVA, E. Trabalho e desgaste mental: o direito de ser dono de si mesmo. São Paulo: Cortez, 2011.

SILVA, S. P.; GOES, F. L.; ALVAREZ, A. R. Situação social das catadoras e dos catadores de material reciclável e reutilizável. Ipea: Brasília, 2013 
SILVA, M. de F. G.; NOBRE, M. N. S. Racismo, exclusão social e a construção da identidade das crianças negras no Brasil. Socialiando FJV, v. 4, n. 1, p. 20-34, 2017.

SIQUEIRA, M. M.; MORAES, M. S. Saúde coletiva, resíduos sólidos urbanos e os catadores de lixo. Ciência e Saúde Coletiva, v. 14, n. 16, 2009.

SOUZA, D. O. A saúde na perspectiva da 'Ontologia do Ser Social'. Trabalho, Educação, Saúde, v. 2, n. 14, p: 337-354, 2016.

\section{Nota}

${ }^{1}$ D. de O. Souza participou da delimitação do problema de pesquisa, definiçáo do percurso metodológico, análise dos dados, redaçáo e revisão final do artigo. L. B. dos Santos participou da concepção do estudo, coleta de dados e redaçáo do artigo. 


\section{Abstract}

\section{Human biopsychic nexus in the context of garbage collectors from an association in the city of Arapiraca-AL, Brazil}

The study aimed to analyze the human biopsychic nexus of recyclable material collectors in an association. This is a qualitative study, carried out in 2017, in the city of Arapiraca-AL, Brazil. From a semi-structured interview script, seven waste collectors were interviewed. The script covered four axes: sociodemographic, work process, consequences of the scavenging activity and general living conditions, making it possible to gather elements to analyze the "human biopsychic nexus" of this group, as proposed by Laurell and Noriega. We identified some of the workloads that the collectors are exposed to, such as the mechanical, psychological and physiological loads related to the organization of the work process. The phenomenon of "suffering normality" is among waste collectors, embodying a kind of pseudo-protection mechanism of the activity that, although it causes illness, offers them some sustenance. Biological loads were also identified by contact with contaminated material, sharps and insects. Workloads make up a broader process in which general living conditions enhance the process of wear and tear, as these collectors face social problems such as lack of sanitation, safety, health and education. Therefore, it is a "human biopsychic nexus" in which the disease overlaps with health.

> Keywords: garbage collectors; social conditions; occupational health. 